\title{
Novel poly (3, 4-ethylenedioxythiophene)/reduced graphene oxide incorporated with manganese oxide/iron oxide for supercapacitor device
}

\begin{abstract}
A new composite namely PEDOT/RGO/MnO $2 / \mathrm{Fe}_{2} \mathrm{O}_{3}$ was successfully developed from mixed metal oxides $\left(\mathrm{MnO}_{2}\right.$ and $\left.\mathrm{Fe}_{2} \mathrm{O}_{3}\right)$ incorporated with poly(3,4-ethylenedioxythiophene) (PEDOT) and reduced graphene oxide (RGO). The surface morphology of the prepared composite revealed that $\mathrm{MnO}_{2}$ and $\mathrm{Fe}_{2} \mathrm{O}_{3}$ particles were successfully coated on the wrinkles and curly like-sheets of PEDOT/RGO in order to prevent aggregation of RGO layers and the composite was able to retain $80 \%$ of its initial specific capacitance in $1 \mathrm{M} \mathrm{KCl}$. The PEDOT/RGO/MnO$/ \mathrm{Me}_{2} \mathrm{O}_{3}$ composite with $\mathrm{Mn}: \mathrm{Fe}$ molar ratio of 2:3 displayed the highest specific capacitance of $287 \mathrm{~F} / \mathrm{g}$ indicating that $\mathrm{Mn}: \mathrm{Fe}$ molar ratio gives significant effect on the super capacitive performance of the composite. The specific capacitance of PEDOT/RGO/ $/ \mathrm{MnO}_{2} / \mathrm{Fe}_{2} \mathrm{O}_{3}$ was higher than the composites with monometallic oxide i.e. $\mathrm{PEDOT} / \mathrm{RGO} / \mathrm{MnO}_{2}$ and PEDOT/RGO/Fe $2 \mathrm{O}_{3}$. The PEDOT/RGO/MnO$/ \mathrm{Fe}_{2} \mathrm{O}_{3}$ composite also revealed the lowest charge transfer resistance that leads to the superior supercapacitive performance. The specific energy and specific power of PEDOT/RGO/MnO $/ \mathrm{Fe}_{2} \mathrm{O}_{3}$ composite were $11 \mathrm{Wh} / \mathrm{kg}$ and $1900 \mathrm{~W} / \mathrm{kg}$ at $4 \mathrm{~A} / \mathrm{g}$, respectively. The results showed that the $\mathrm{PEDOT} / \mathrm{RGO} / \mathrm{MnO}_{2} / \mathrm{Fe}_{2} \mathrm{O}_{3}$ composite is a promising electrode material for high-performance supercapacitor.
\end{abstract}

